\title{
Effects of Supplementation with Glutathione and its Precursors on Athlete Performance
}

\author{
Krzysztof Grucza ${ }^{1,2,3}$, Piotr Chołbiński², Dorota Kwiatkowska*2,3 and Mirosław Szutowski ${ }^{1}$ \\ ${ }^{1}$ Medical University of Warsaw, Faculty of Pharmacy, Department of Applied Toxicology, Warsaw, Poland \\ ${ }^{2}$ Institute of Sport - National Research Institute, Department of Anti-Doping Research, Warsaw, Poland
}

${ }^{3}$ Polish Anti-Doping Laboratory, Warsaw, Poland

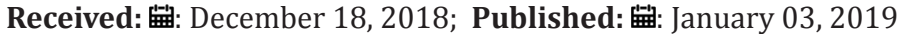

*Corresponding author: Dorota Kwiatkowska, Department of Anti-Doping Research, Poland

\begin{abstract}
Glutathione (GSH) is a thiol-containing tripeptide consisting of glutamate (Glu), cysteine (Cys) and glycine (Gly), which plays central roles in the defense against oxidative damage and in signaling pathways. The cellular concentration of GSH and its oxidative state (GSSG), and their molar ratio are indicators of cell functionality and redox state. Glutathione is the most important antioxidant in human organism. Its level can be increased by supplementation with glutathione precursors. Furthermore, glutathione is the most popular drug (supplement) used by athletes and people remaining in physical activity. The increase in GSH body content can be achieved by supplementation with N-acetyl-L-cysteine (NAC), $\alpha$ - lipoic acid (ALA), whey preparation or L-glutamine. There are many scientific reports showing a key role of glutathione in treatment of many diseases. Furthermore, authors demonstrated improvement of the sport performance and physical condition of athletes by supplementation of glutathione and glutathione precursors.
\end{abstract}

Keywords: Glutathione; Glutathione Precursors; Oxidative Stress; Physical Activity; Athletes Performance

Abbreviations: ROS: Reactive Oxygen Species; NAC: N-acetyl-L-cysteine; ALA: $\alpha$ - Lipoic Acid; GCL: Glutamate Cysteine Ligase; GS: GSH Synthetase; RN: Reactive Nitrogen OS: Oxygen Species; IRS: Insulin Receptor Substrate; NS: Nutritional Supplements

\section{Introduction}

Intensive exercise is related to an increased generation of reactive oxygen species (ROS), the main cause of oxidative stress, as a consequence of higher energy demand [1,2]. In active tissues such as skeletal muscles, ROS activity results mainly from mitochondria damage and may impair the muscle force production. Therefore, many athletes consume antioxidant supplements to suppress muscle fatigue or to facilitate the process of recovery. Whether such antioxidant supplementation has beneficial effects on sport performance and health is a matter of controversy which seems to stem from considerable differences in study designs [3]. Some authors report that antioxidant supplementation, especially a prolonged one, may have deleterious effects on health and sport performance, e.g. by down regulating natural ROS quenching mechanisms or hampering organism adaptation to increased physical exercise [4-8]. Such results are in line with the free radical theory of development which posits that formation of reactive species plays a very important role in development of organisms and their adaptation to environmental changes [9]. Other studies report that antioxidant supplementation may lead to increased sport performance or shortens the process of post-exercise recovery; the effects highly desired by competitive athletes. A common feature of those studies seems to be a short and acute supplementation period, usually a few days or weeks long, which perhaps still allows for triggering the adaptation mechanisms in response to increased production of ROS. These studies are of the main interest of this review.

\section{Glutathione - Physiological Significance and Therapeutic Potential}

Glutathione ( $\gamma$-L-glutamyl-L-cysteinyl-glycine, GSH) plays a very important role in physical exercise by controlling the level of oxidative stress. It is the major endogenous intracellular antioxidant and currently one of the most studied substances of this class. It is synthesized primarily in the hepatic cells and has numerous physiological functions, including protection of cells against oxidative stress, detoxication of toxins and carcinogens, posttranslational regulation of protein function, and maintenance of immune function of the immune system. In human body, GSH is 
synthesized by sequential addition of the precursor amino acids, cysteine (Cys), glutamic acid (Glu) and glycine (Gly), through enzymatic catalysis by two ATP-dependent enzymes namely, glutamate cysteine ligase (GCL) and GSH synthetase (GS) $[10,11]$. The maintenance of tissue levels of GSH is critical for maintaining health, preventing diseases and age-related biological insults [12]. Human blood plasma contains low amounts of reduced glutathione that has been shown to increase post-exercise [13].

Almost all of blood glutathione represents blood cell content, mainly that of the erythrocytes. Oxidation of GSH to glutathione disulfide (GSSG) is a sensitive marker of the oxidative stress $[14,15]$. Scientific reports show that high levels of reactive oxygen species (ROS) and low GSH levels are associated with increased risk of numerous diseases. The most well-known include neurodegenerative diseases (particularly Parkinson's and Alzheimer's disease), pulmonary diseases (chronic obstructive pulmonary disease, asthma, and acute respiratory distress syndrome), cystic fibrosis, immune diseases (autoimmune disease), cardiovascular diseases (hypertension, myocardial infarction, cholesterol oxidation) as well as diseases associated with age-related oxidation (cataract, muscular degeneration, hearing impairment, and glaucoma), and cancer [16,17]. The list of conditions associated with impaired GSH homeostasis continues to grow and reflects the importance and diversity of glutathione cellular functions [17].

Thus, GSH application as a therapeutic agent is widely discussed in the literature [18-20]. Reports indicate the use of oral supplementation with GSH and its precursors for treatment of acute respiratory distress syndrome [21], in patients with cystic fibrosis [22], in autism spectrum disorders [23], for improvement of liver biochemistry (e.g. in of nonalcoholic steatohepatitis patients) [24], for significant improvement and slowing of the Parkinson`s disease progress [25], as a strategy in Alzheimer's disease [26], in patients with peripheral artery disease [27], in children with chronic otitis [28], for the treatment of mercury toxicity [29], and in schizophrenia and bipolar disorder [30]. The ability to form reduced glutathione diminishes with age [31-33]. Therefore, restoration of the antioxidant potential of the body for therapeutic purposes may be required in such individuals. This could be obtained by employing various strategies such as supplementation with glutathione, its precursors, or other substances that indirectly modify GSH level.

\section{Glutathione Supplementation and Sport Performance}

The data on effects of direct GSH supplementation and sport performance is scarce. However, a recent study has showed that 2 week oral GSH supplementation (1g/day) may alleviate fatigue in healthy men during and after cycling exercise [10]. It is worth noting that the positive effects of GSH supplementation on sport performance could be observed with just minute changes in its blood levels. Data from mice suggests that this effect may result from a facilitated aerobic metabolism of lipids in skeletal muscles due to the increased mitochondria biogenesis and decreased muscle acidosis [10]. Interestingly, the observed upregulation of factors involved in mitochondria biogenesis was rather unexpected as antioxidant supplementation (e.g. with vitamin $\mathrm{C}$ or E) has been shown to suppress their levels [6-8]. Thus, it is tempting to speculate that these changes manifest a GSH J-shaped activity as a signaling factor rather than an antioxidant. It is still to be determined whether it is the effect of direct GSH absorption, absorption of GSH precursors resulting from its hydrolysis, or both. Additionally, it is an interesting question as the bioavailability of ingested GSH has long been considered negligible.

However, recent studies suggest that it can be absorbed in the intact form $[34,35]$ and the elevation of GSH body levels following its oral supplementation has been already reported [2,12,34, 36,37]. The concentration of GSH may be increased by supplementation oral or sublingual form of glutathione. Schmitt et al. demonstrated the superiority of sublingual form of GSH over oral form. Within this study 20 volunteers with metabolic syndrome received $450 \mathrm{mg} /$ day of both forms of GSH [37]. Other studies revealed that GSH supplementation may improve the performance in mice. Leewuenburgh et al. demonstrated improvement in endurance performance and lower muscle lipid peroxidation during prolonged exercise (mice were given $6 \mathrm{mmol} / \mathrm{kg}$ body (via intraperitoneal injection) $1 \mathrm{~h}$ before exercise [38]. Furthermore, a positive effect of GSH supplementation on swimming performance was reported by Novelli et al. [39]. Mice received GSH (by intraperitoneal injection) in doses of 500,750 and $1000 \mathrm{mg} / \mathrm{kg}$. Increased swimming endurance (102.4\%, 120.0\% and 140.7\%, respectively) was observed. GSH of $250 \mathrm{mg} / \mathrm{kg}$ did not affect endurance when injected in a single dose but increased it by $103.7 \%$ when injected once a day for 7 days [39].

\section{Glutathione Precursors}

The body stores of GSH can be restored or increased by supplementation with GSH precursors, of which N-acetyl-L-cysteine has gained probably the most attention. It is the $\mathrm{N}$-acetylated form of the amino acid L-cysteine which can be administered orally. It is a thiol donor with nonspecific antioxidant properties $[19,40]$. NAC has been used in clinical practice to facilitate GSH biosynthesis, which may improve the intracellular antioxidant defense system and, possibly, decrease the damaging effects of ROS. Due to physiological decrease in GSH levels with age [32], it seems that NAC supplementation would be the most efficient in young patients, due to the age-related decrease in GSH synthesis in older individuals. The latest reports discuss an application of NAC to recovery facilitation after traumatic brain injury, cerebral ischemia, and in treatment of cerebrovascular vasospasm after subarachnoid hemorrhage [42]. Other therapeutic indications were achieved on rodent experimental models [43,44].

In the field of sport nutrition, there is a growing interest about NAC. It has been shown that NAC supplementation for seven days at $1200 \mathrm{mg}$ per day may improve the muscle fatigue and increase the VO2 max in sedentary men [45]. Another study conducted by Kelly et al. showed that $1800 \mathrm{mg}$ of NAC ingested 45 minutes prior to exercise test reduced respiratory muscle fatigue in men during heavy exercise [46]. Moreover, NAC infusion $(125 \mathrm{mg} / \mathrm{kg} / \mathrm{h}$ for $15 \mathrm{~min}$ and then at $25 \mathrm{mg} / \mathrm{kg} / \mathrm{h}$ for $20 \mathrm{~min}$ before and throughout the exercise) during prolonged, submaximal cycling exercise was 
reported to increase its muscle content as well as skeletal muscle cysteine, cystine, and glutathione availability during the test. The NAC administration resulted also in a substantial enhancement of performance in well trained individuals [47]. Sinha-Hikim et al. demonstrated a beneficial effect of NAC supplementation $(3 \mathrm{mg} / \mathrm{kg}$ feed) to attenuate loss of muscle mass associated with aging in mice [48]. Another study showed that treatment with NAC represented an important factor in the defense against muscle soreness. Furthermore, it seems that NAC has some anti-inflammatory effects and acts on the downregulation of proinflammatory cytokines [49].

These performance-enhancing effects appear to be mediated by increases in circulating and myocyte levels of Cys and GSH $[47,50,51]$. However, the exact mechanism of NAC action is still to be elucidated and published data suggests that it may be a product of at least three different NAC activities. As NAC can be hydrolysed to Cys, which is a limiting factor of GSH synthesis, its supplementation may increase total GSH levels and GSH/GSSG ratio [52-55]. Additionally, it may reduce oxidated substances such as cystine or GSSG [50,55] or may simply modify the oxidative state of the organism by direct ROS quenching. Further research will need to determine which of these mechanisms predominate at a given condition. Nevertheless, recent studies have shown that the antioxidant activity of NAC may prolong the exercise time to fatigue, at least partially by the enhancement of $\mathrm{Na}+\mathrm{K}+-$ pump activity [51]. The pump is involved in maintenance of the cellular $\mathrm{Na}+/ \mathrm{K}+$ homeostasis, disturbance of which may impair muscle force development. NAC has been shown to indirectly prevent a ROS-mediated $\mathrm{Na}+\mathrm{K}+-$ pump by improving the ROS scavenging mechanisms in the cell thereby protecting the SH groups on the transporter [51].

Additionally, NAC administration attenuates expression of mRNA coding for one of the isoforms of $\mathrm{Na}+\mathrm{K}+$ catalytic subunit; the process known to be unregulated in response to exercise [56]. It is therefore possible that upregulation of this mechanism is suppressed due to the lowered ROS levels and the consequent reduced turnover of the transporter. Strenuous exercise is also known to induce muscle injury accompanied with an inflammatory response which may cause a neutrophile invasion into the tissue and local excessive ROS production [57]. Importantly, NAC supplementation $(200 \mathrm{mg} /$ day) before incremental cycling test has been shown to prevent the increase in capacity of neutrophils to generate ROS in untrained healthy men [55]. In another study conducted on rowers ( $6 \mathrm{~g}$ for three days before completing $6 \mathrm{~min}$ of maximal exercise) by Peake et al. [58] showed that NAC may cause a significant reduction of in vitro neutrophil ROS production below the pre-exercise values. Hence, NAC may prevent infliction of additional oxidative stress on the damaged tissue by ROS of neutrophile origin. Such NAC activity may be advantageous, especially in cases of prolonged exercise or during the recovery period [57].

A positive effect of supplementation by NAC (oral or intravenous) before (or during) trial on athletes performance are also described in [59-63]. Another glutathione precursor is glutamylcystin. It can be found in some of whey preparations such as Immunocal and is more readily absorbed form of Cys. In general, whey protein is a collective term that encompasses a range of soluble protein fractions found in milk. Whey protein products are classified into several categories based on their macronutrient ratios that suit a variety of food manufacturing purposes. At the molecular level, stimulating protein synthesis and minimizing protein breakdown are the two processes essential to efficient recovery after exercise $[64,65]$. The effect of Immunocal supplementation on enhancement of muscular performance was showed by Lands et al. [64]. In that study, an increased muscle performance (ability to generate more power to perform more work during a 30s of maximal effort) and increased lymphocyte glutathione concentrations of 35,5\% were observed in "Immunocal group".

Furthermore, the supplemented group also spent more time in activity, whereas there was no change in the control group. Similar results were showed by Karelis et al. Participants ingested 20g/day a cysteine-rich whey protein isolate (Immunocal $\rightarrow$ ), whereas the control group received casein at the same dosing. All participants performed the same resistance training program (3 times per week). Results from this study showed a significant increase in muscle strength $(\sim+10 \%)$ in subjects who were supplemented with Immunocal $\rightarrow$ versus casein [66]. Supplementation with whey proteins is common in medicine. The results showing that oral administration of whey proteins may indeed lead to an increase in plasma glutathione levels were shown by Micke et al. in patients with advanced HIV-infection [67]. In another study by Ross et al. mice received Immunocal $\rightarrow 660 \mathrm{mg} / \mathrm{kg} /$ day. This supplementation significantly reduced age-associated decline in skeletal muscle functions. Furthermore, it significantly delayed the clinical onset of neuromuscular disease [68].

\section{L-Glutamine}

Athletes may increase glutathione body level bysupplementation with L- glutamine (Gln), which is a naturally occurring nonessential neutral amino acid [69]. It is important in the acid base regulation, gluconeogenesis, and as a precursor of nucleotide bases and the antioxidant glutathione. Gln is the most abundant free amino acid in human muscle and plasma. Other dietary sources of Gln for athletes may include protein supplements such as whey protein and protein hydrolysates $[69,70]$. Various manufacturers and suppliers of Gln supplements claim that their products have features that may benefit athletes: nutritional support for the immune system and prevention of infection, improved gut barrier function and reduced risk of endotoxemia, improved intracellular fluid retention (i.e. a volumizing effect), more rapid water absorption from the gut, stimulation of muscle glycogen synthesis, muscle protein synthesis and muscle tissue growth, reduction in muscle soreness and improved muscle tissue repair, enhanced buffering capacity, and improved high intensity exercise performance [69,71].

Gln is an important fuel for some cells of the immune system and may have specific immunostimulatory effects. Furthermore, Gln have a positive effect on liver function [72-74]. Koo et al. [75] demonstrated that glutamine supplementation by rowers $(6 \mathrm{~g} /$ day) had a positive effect on the decrease in fatigue factor stimulation at 
the recovery stage after maximal intensity exercise compared with supplementation with the placebo. Furthermore, enhanced immune function and the defensive inflammatory reaction were observed. Similar effects were obtained by Sasaki et al. [76]. Moreover, Gln could be the best of choice as a precursor of glutathione, because it is the main systemic transporter of nitrogen in mammals and its carbon skeleton may be used in glutathione synthesis [70,74]. It has been showed that periods of very heavy training are associated with a chronic reduction in plasma concentrations of Gln which may be partly responsible for the immunodepression effect apparent in many endurance athletes [77].

A lot of research concerning on oral supplementation with Gln and its effect on physical performance, took place in Iran $[1,78,79]$. Research conducted by Dabidi Roshan focused on immunological aspect. During the trial, active young males (mean 18 years old) received $0.1 \mathrm{~g} / \mathrm{kg}$ of Gln. Available data did not support the contention that the post-exercise change in some immune indices was caused by a decrease in plasma glutamine concentration. Glutamine supplementation attenuated the exercise-induced decline in glutamine concentration. Similar effect were obtained in Castell et al. [80] research. Glutamine supplementation at $0.1 \mathrm{~g} / \mathrm{kg}$ caused a significant increase in the plasma glutamine concentration within $30 \mathrm{~min}$ in healthy humans. Furthermore, glutamine supplementation caused that the ratio of CD4+ helper/ CD8+ suppressor cells in blood samples taken $1 \mathrm{~h}$ after a marathon and after a drink of either glutamine or placebo, was significantly lower in the placebo group than in the glutamine group.

Oral supplementation of glutamine $(0.35 \mathrm{~g} / \mathrm{kg} / \mathrm{day})$ by 15 non-athlete male students for 8 weeks, caused significantly greater increases in upper and lower body strength, explosive muscular power, blood testosterone, GH and IGF-1 when compared to the placebo group. Furthermore, in the study group there was improved body composition (increased body mass, fat-free mass and reduced body fat) and vertical jump (62.31 \pm 5.22 pre- and $67.11 \pm 4.44$ post- supplementation) [79]. Glutamine supplementation plays a key role in recovery after muscle injury. It has been shown that such supplementation $(0.1 \mathrm{~g} / \mathrm{kg}$ of L-glutamine) caused attenuated delayed onset muscle soreness effects in "supplementation" group [1]. Oral glutamine supplementation influenced also athletes`endurance. Glutamine consumed by nine male soccer players caused great improvement in the time and distance covered. One group consumed carbohydrate with peptide glutamine, while the second group carbohydrate alone. Total distance covered in first group was $15571 \mathrm{~m}$ and $12750 \mathrm{~m}$ in second group. Furthermore, the first group experienced less fatigue. There are few studies that associate the effect of glutamine with the performance of athletes and thus the mechanisms involved are still unclear [81]. Studies on glutamine were also conducted in rodents. Eleven male mice administered an L-glutamine supplement through their drinking water for four weeks. The average contractile force obtained from these eleven experimental mice was higher $(0.0018 \mathrm{~N} / \mathrm{g})$ than in the control group $(0.0008 \mathrm{~N} / \mathrm{g})$. In study group the muscle weight mass $(2,4 \mathrm{~g})$ was also increased in comparison to control group $(1,66 \mathrm{~g})$ [82].

\section{Alpha-Lipoic Acid}

Alpha-lipoic acid (LA) is a naturally occurring dithiol compound synthesized enzymatically in the mitochondria from octanoic acid [83]. LA is also a dietary supplement that is known to strengthen the antioxidant network [84]. Like glutathione, LA is present in two states, namely, oxidated ( $\alpha$ LA) and reduced (DHLA) [65]. LA is absorbed in the intact form from dietary sources, and it transiently accumulates in many tissues [83]. LA has already been described as a potent biological antioxidant [85] and has been demonstrated to increase muscle phosphocreatine levels and muscle total creatine concentrations [86]. Research conducted by Zembron Lacny et al. [87] showed that LA has a clear pro-glutathione effect in physically active individuals after 8-days supplementation with $600 \mathrm{mg}$ LA daily doses. Administration of LA resulted in declined carbonyl groups and thiobarbituric acid-reactive substances in plasma compared with control group, which are products of lipid peroxidation and protein carbonylation. Both factors are markers of oxidative damage, which are indirectly correlated with total antioxidants status [87].

Another very important factor in the context of physical exercise is Interleukin-6 (IL-6). IL-6 is a cytokine which plays a role in muscle energy homeostasis during physical exercise. Lappalainen [88] investigated the effect of LA administration on IL-6. IL-6 is an immunomodulatory cytokine produced mainly by the cells of the immune system and is considered as a marker of inflammation. However, IL-6 is also secreted by the skeletal muscles and plasma levels of IL-6 may rise up to 100-fold after strenuous physical exercise [89]. IL-6 can improve skeletal muscle energy supply and assist in the maintenance of stable blood glucose levels by stimulating lipolysis in the adipose tissue and augmenting hepatic glycogenolysis [90,91]. Lappalainen [88] has indicated that exercise increases serum IL-6 levels irrespective of diurnal variation and showed that supplementation with LA had no beneficial effect on exercise performance and exercise-induced IL-6 response.

Some publications also presents a beneficial effect of supply LA in the haematological context. Sixteen healthy young males participated in the randomized and placebo-controlled study designed in order to show the changes in the hematological response through the combination of LA intake with running as an eccentric exercise. This study confirmed the antioxidative properties of LA, through lipid and protein protection against over-activity of reactive nitrogen/oxygen species (RN/OS) [92]. Furthermore, it is known that EPO stimulates proliferation of myoblasts in skeletal muscle and has a potential role in muscle mass maintenance [93]. Results from research indicated a possible use of LA to improve EPO production and skeletal muscle regeneration through changes in the reactive nitrogen/oxygen species (RN/OS) ratio at rest and after exercise. $\alpha$-Lipoic acid enhanced EPO production both before exercise and during recovery. EPO level was especially high at $48 \mathrm{~h}$ after exercise [92].

It is know that, during physical exercise there are intense changes in the circulatory system and changes associated with 
thermoregulation. Therefore, LA is also a research object in this context. Polyviou et al. [94] showed that a supplement containing LA provides improvements in the thermoregulatory and cardiovascular responses in training cyclists during exercise in the heat. Thus, application of LA can be useful for athletes, who are training at high temperature. Insulin and glucose play a very important role in physical exercise. There are many publications focused on supplementation with LA in order to improve insulin activity and glucose utilization in humans [95], rodents [96] and chickens [97]. Saengsirisuwan et al. [98] showed that LA supplementation improved insulin response in rats as evidenced by increased expression of insulin receptor substrate-1 (IRS-1) signaling in skeletal muscle which is a primary site for glucose uptake and storage.

\section{Conclusion}

Undeniably, supplements play key role in sport. On the other hand, there is a growing evidence suggesting that nutritional supplementation is strongly associated with doping use in elite and amateur sportsmen [99] and nutritional supplements (NS) have been promoted as safe alternatives in order to enhance performance. However, its use has also been associated with an increased risk of doping. Athletes who have used supplements, become more favorable toward doping, prior to engaging in this behavior [99]. Barkoukis et al. (2015) [99] investigated, the cognitive and behavioral components of the association between NS use and doping among adolescent sub-elite athletes. The results of the study on 650 adolescent athletes group showed that NS users who did not report doping use had significantly stronger doping intentions and more positive attitudes and favorable beliefs toward doping use, in comparison with athletes who did not use NS. Glutathione, its precursors and Sulphur compounds are considered as a potentially therapeutic wide spectrum agents in clinical practice. The need for healing injuries after intensive exercises justifies use of these compounds by athletes. Further research is being conducted on markers for detection of early signs of overload exercise athletes, such as glutamine, glutamate and glutamine/ glutamate ratio [100]. The use of performance-enhancing substances is frequent and popular in both amateur and professional sports [101]. However, it can be also done unintentionally while taking dosages of NS that are contaminated or faked with doping substances prohibited by World Anti-Doping Agency (e.g. steroids, stimulants, narcotics) [99,102104]. Proteins, amino acids, creatine, multivitamins and mineral and herbal products are used for performance enhancement in the elite, amateur, and recreational sports across age groups [105-109]. A growing body of research implies that the NS use can serve as a "gateway" to doping [99].

\section{Acknowledgement}

Ministry of Sport and Tourism of the Republic of Poland, Grant/ Award Number: 2018.0029/ 0305/UDOT/BM.

\section{References}

1. Rahmani Nia F, Farzaneh E, Damirchi A, Shamsi Majlan A (2013) Effect of L-glutamine supplementation on electromyographic activity of the quadriceps muscle injured by eccentric exercise. Iran J Basic Med Sci 16(6): 808-812.
2. Ramires PR, Ji LL (2001) Glutathione supplementation and training increases myocardial resistance to ischemia-reperfusion in vivo. Am J Physiol Heart Circ Physiol 281(2): 679-688.

3. Peternelj TT, Coombes JS (2011) Antioxidant supplementation during exercise training: beneficial or detrimental? Sports Med 41(12): 10431069.

4. Silveira LR, Pilegaard H, Kusuhara K, Curi R, Hellsten Y (2006) The contraction induced increase in gene expression of peroxisome proliferator-activated receptor (PPAR)-gamma coactivator 1alpha (PGC1alpha), mitochondrial uncoupling protein 3 (UCP3) and hexokinase II (HKII) in primary rat skeletal muscle cells is dependent on reactive oxygen species. Biochim Biophys Acta 1763(9): 969-976.

5. Draeger CL, Naves A, Marques N, Baptistella AB, Carnauba RA, et al. (2014) Controversies of antioxidant vitamins supplementation in exercise: ergogenic or ergolytic effects in humans? J Int Soc Sports Nutr 11(1): 4 .

6. Schmidt HH, Stocker R, Vollbracht C, Paulsen G, Riley D, et al. (2015) Daiber A, Cuadrado A. Antioxidants in Translational Medicine. Antioxid Redox Signal 23(14): 1130-1143.

7. Paulsen G, Cumming KT, Holden G, Hallen J, Ronnestad BR, et al. (2014) Vitamin $\mathrm{C}$ and $\mathrm{E}$ supplementation hampers cellular adaptation to endurance training in humans: a double-blind, randomised, controlled trial. J Physiol 592(8): 1887-1901.

8. Gomez Cabrera MC, Salvador Pascual A, Cabo H, Ferrando B, Vina J (2015) Redox modulation of mitochondriogenesis in exercise. Does antioxidant supplementation blunt the benefits of exercise training? Free Radic Biol Med 86: 37-46.

9. Hitchler MJ, Domann FE (2007) An epigenetic perspective on the free radical theory of development. Free Radic Biol Med 43(7): 1023-1036.

10. Aoi W, Ogaya Y, Takami M, Konishi T, Sauchi Y, et al. (2015) Glutathione supplementation suppresses muscle fatigue induced by prolonged exercise via improved aerobic metabolism. J Int Soc Sports Nutr 12: 7.

11. Lu SC (2009) Regulation of glutathione synthesis. Mol Aspects Med 30(1-2): 42-59.

12. Richie JP, Nichenametla S, Neidig W, Calcagnotto A, Haley JS, et al. (2015) Randomized controlled trial of oral glutathione supplementation on body stores of glutathione. Eur J Nutr 54(2): 251-263.

13. Cakir Atabek H, Ozdemir F, Colak R (2015) Oxidative stress and antioxidant responses to progressive resistance exercise intensity in trained and untrained males. Biol Sport 32(4): 321-328.

14. Sen CK (1999) Glutathione homeostasis in response to exercise training and nutritional supplements. Mol Cell Biochem 196(1-2): 31-42.

15. Sen CK, Packer L (2000) Thiol homeostasis and supplements in physical exercise. Am J Clin Nutr 72(2): 653-669.

16. Shimizu H, Kiyohara Y, Kato I, Kitazono T, Tanizaki Y, et al. (2004) Relationship between plasma glutathione levels and cardiovascular disease in a defined population: the Hisayama study. Stroke 35(9): 20722077.

17. Townsend DM, Tew KD, Tapiero H (2003) The importance of glutathione in human disease. Biomed Pharmacother 57(3-4): 145-155.

18. Cacciatore I, Cornacchia C, Pinnen F, Mollica A, Di Stefano A (2010) Prodrug approach for increasing cellular glutathione levels. Molecules 15(3): 1242-1264.

19. Lushchak VI (2012) Glutathione homeostasis and functions: potential targets for medical interventions. J Amino Acids 2012: 736837.

20. McPherson RA, Hardy G (2011) Clinical and nutritional benefits of cysteine-enriched protein supplements. Curr Opin Clin Nutr Metab Care 14(6):562-568.

21. Soltan Sharifi MS, Mojtahedzadeh M, Najafi A, Reza Khajavi M, Reza Rouini $\mathrm{M}$, et al. (2007) Improvement by $\mathrm{N}$-acetylcysteine of acute respiratory 
distress syndrome through increasing intracellular glutathione, and extracellular thiol molecules and anti-oxidant power: evidence for underlying toxicological mechanisms. Hum Exp Toxicol 26(9): 697-703.

22. Grey V, Mohammed SR, Smountas AA, Bahlool R, Lands LC (2003) Improved glutathione status in young adult patients with cystic fibrosis supplemented with whey protein. J Cyst Fibros 2(4): 195-198.

23. Kern JK, Geier DA, Adams JB, Garver CR, Audhya T, et al. (2011) A clinical trial of glutathione supplementation in autism spectrum disorders. Med Sci Monit 17(12): 677-682.

24. Chitapanarux T, Tienboon P, Pojchamarnwiputh S, Leelarungrayub D (2009) Open-labeled pilot study of cysteine-rich whey protein isolate supplementation for nonalcoholic steatohepatitis patients. J Gastroenterol Hepatol 24(6): 1045-1050.

25. Sechi G, Deledda MG, Bua G, Satta WM, Deiana GA, et al. (1996) Reduced intravenous glutathione in the treatment of early Parkinson's disease. Prog Neuropsychopharmacol Biol Psychiatry 20(7): 1159-1170.

26. Butterfield DA, Pocernich CB, Drake J (2002) Elevated glutathione as a therapeutic strategy in Alzheimer's disease. Drug Development Research 56(3): 428-437.

27. Arosio E, De Marchi S, Zannoni M, Prior M, Lechi A (2002) Effect of glutathione infusion on leg arterial circulation, cutaneous microcirculation, and pain-free walking distance in patients with peripheral obstructive arterial disease: a randomized, double-blind, placebo-controlled trial. Mayo Clin Proc 77(8): 754-759.

28. Testa B, Testa D, Mesolella M, D’Errico G, Tricarico D, et al. (2001) Management of chronic otitis media with effusion: the role of glutathione. Laryngoscope 111(8): 1486-1489.

29. Patrick L (2002) Mercury toxicity and antioxidants: Part 1: role of glutathione and alpha-lipoic acid in the treatment of mercury toxicity. Altern Med Rev 7(6): 456-471.

30. Berk M, Copolov DL, Dean O, Lu K, Jeavons S, et al. (2008) N-acetyl cysteine for depressive symptoms in bipolar disorder-a double-blind randomized placebo-controlled trial. Biol Psychiatry 64(6): 468-475.

31. Lenton KJ, Therriault H, Cantin AM, Fulop T, Payette H, et al. (2000) Direct correlation of glutathione and ascorbate and their dependence on age and season in human lymphocytes. Am J Clin Nutr 71(5): 1194-1200.

32. Van Lieshout EM, Peters WH (1998) Age and gender dependent levels of glutathione and glutathione S-transferases in human lymphocytes. Carcinogenesis 19(10): 1873-1875.

33. Watson SN, Lee JR, Risling TE, Hermann PM, Wildering WC (2014) Diminishing glutathione availability and age-associated decline in neuronal excitability. Neurobiol Aging 35(5): 1074-1085.

34. Bachhawat AK, Thakur A, Kaur J, Zulkifli M (2013) Glutathione transporters. Biochim Biophys Acta 1830(5): 3154-3164.

35. Kovacs Nolan J, Rupa P, Matsui T, Tanaka M, Konishi T, et al. (2014) In vitro and ex vivo uptake of glutathione (GSH) across the intestinal epithelium and fate of oral GSH after in vivo supplementation. J Agric Food Chem 62(39): 9499-9506.

36. Park EY, Shimura N, Konishi T, Sauchi Y, Wada S, et al. (2014) Increase in the protein-bound form of glutathione in human blood after the oral administration of glutathione. J Agric Food Chem 62(26): 6183-6189.

37. SchmittB, Vicenzi M, Garrel C, Denis FM (2015) Effects of N-acetylcysteine, oral glutathione (GSH) and a novel sublingual form of GSH on oxidative stress markers: A comparative crossover study. Redox Biol 6: 198-205.

38. Leeuwenburgh C, Ji LL (1998) Glutathone and glutathione ethyl ester supplementation of mice alter glutathione homeostasis during exercise. J Nutr 128(12): 2420-2426.

39. Novelli GP, Falsini S, Bracciotti G (1991) Exogenous glutathione increases endurance to muscle effort in mice. Pharmacol Res 23(2): 149-155.
40. Samuni Y, Goldstein S, Dean OM, Berk M (2013) The chemistry and biological activities of $\mathrm{N}$-acetylcysteine. Biochim Biophys Acta 1830(8): 4117-4129.

41. Zhang F, Lau SS, Monks TJ (2011) The cytoprotective effect of N-acetyl-Lcysteine against ROS-induced cytotoxicity is independent of its ability to enhance glutathione synthesis. Toxicol Sci 120(1): 87-97.

42. Bavarsad Shahripour R, Harrigan MR, Alexandrov AV (2014) $\mathrm{N}$-acetylcysteine (NAC) in neurological disorders: mechanisms of action and therapeutic opportunities. Brain Behav 4(2): 108-122.

43. Clark J, Clore EL, Zheng K, Adame A, Masliah E, et al. (2010) Oral N-acetylcysteine attenuates loss of dopaminergic terminals in alpha-synuclein overexpressing mice. PLoS One 5(8): e12333.

44. Sudha M, Rajkumar D, Felix JW (2013) Protective effect of glutathione against isoproterenol induced myocardial injury in rats. Indian J Physiol Pharmacol 57(2): 132-137.

45. Leelarungrayub D, Khansuwan R, Pothongsunun P, Klaphajone J (2011) $\mathrm{N}$-acetylcysteine supplementation controls total antioxidant capacity, creatine kinase, lactate, and tumor necrotic factor-alpha against oxidative stress induced by graded exercise in sedentary men. Oxid Med Cell Longev 2011: pp. 329643.

46. Kelly MK, Wicker RJ, Barstow TJ, Harms CA (2009) Effects of $\mathrm{N}$-acetylcysteine on respiratory muscle fatigue during heavy exercise. Respir Physiol Neurobiol 165(1):67-72.

47. Medved I, Brown MJ, Bjorksten AR, Murphy KT, Petersen AC, et al. (2004) $\mathrm{N}$-acetylcysteine enhances muscle cysteine and glutathione availability and attenuates fatigue during prolonged exercise in endurance-trained individuals. J Appl Physiol (1985) 97(4): 1477-1485.

48. Sinha Hikim I, Sinha Hikim AP, Parveen M, Shen R, Goswami R, et al. (2013) Long-term supplementation with a cystine-based antioxidant delays loss of muscle mass in aging. J Gerontol a Biol Sci Med Sci 68(7): 749-759.

49. Silva LA, Silveira PC, Pinho CA, Tuon T, Dal Pizzol F, et al. (2008) $\mathrm{N}$-acetylcysteine supplementation and oxidative damage and inflammatory response after eccentric exercise. Int J Sport Nutr Exerc Metab 18(4): 379-388.

50. Ferreira LF, Campbell KS, Reid MB (2011) N-acetylcysteine in handgrip exercise: plasma thiols and adverse reactions. Int J Sport Nutr Exerc Metab 21(2): 146-154.

51. Mc Kenna MJ, Medved I, Goodman CA, Brown MJ, Bjorksten AR, et al. (2006) N-acetylcysteine attenuates the decline in muscle $\mathrm{Na}+\mathrm{K}+-$ pump activity and delays fatigue during prolonged exercise in humans. J Physiol 576(1): 279-288.

52. Kuyumcu A, Akyol A, Buyuktuncer Z, Ozmen MM, Besler HT (2015) Improved oxidative status in major abdominal surgery patients after $\mathrm{N}$-acetyl cystein supplementation. Nutr J 14: 4.

53. Holmay MJ, Terpstra M, Coles LD, Mishra U, Ahlskog M, et al. (2013) $\mathrm{N}$-Acetylcysteine boosts brain and blood glutathione in Gaucher and Parkinson diseases. Clin Neuropharmacol 36(4): 103-106.

54. Kasperczyk S, Dobrakowski M, Kasperczyk A, Ostalowska A, Birkner E (2013) The administration of $\mathrm{N}$-acetylcysteine reduces oxidative stress and regulates glutathione metabolism in the blood cells of workers exposed to lead. Clin Toxicol (Phila) 51(6): 480-486.

55. Whillier S, Raftos JE, Chapman B, Kuchel PW (2009) Role of $\mathrm{N}$-acetylcysteine and cystine in glutathione synthesis in human erythrocytes. Redox Rep 14(3): 115-124.

56. Murphy KT, Medved I, Brown MJ, Cameron Smith D, McKenna MJ (2008) Antioxidant treatment with $\mathrm{N}$-acetylcysteine regulates mammalian skeletal muscle $\mathrm{Na}+\mathrm{K}+-\mathrm{ATPase}$ alpha gene expression during repeated contractions. Exp Physiol 93(12): 1239-1248. 
57. Ji LL (2000) Free radicals and antioxidants in exercise and sports. Exercise and Sport Science. In Garrett and D. Kirkendall (Eds.). Lippincott Williams \& Wilkins, Philadelphia, Pennsylvania, United States: pp. 299319.

58. Peake J, Suzuki K (2004) Neutrophil activation, antioxidant supplements and exercise-induced oxidative stress. Exerc Immunol Rev 10: 129-141.

59. Cobley JN, McGlory C, Morton JP, Close GL (2011) N-Acetylcysteine's attenuation of fatigue after repeated bouts of intermittent exercise: practical implications for tournament situations. Int J Sport Nutr Exerc Metab 21(6): 451-461.

60. Matuszczak Y, Farid M, Jones J, Lansdowne S, Smith MA, et al. (2005) Effects of $\mathrm{N}$-acetylcysteine on glutathione oxidation and fatigue during handgrip exercise. Muscle Nerve 32(5): 633-638.

61. Corn SD, Barstow TJ (2011) Effects of oral N-acetylcysteine on fatigue, critical power, and $W^{\prime}$ in exercising humans. Respir Physiol Neurobiol 178(2): 261-268.

62. Bailey SJ, Winyard PG, Blackwell JR, Vanhatalo A, Lansley KE, et al. (2011) Influence of $\mathrm{N}$-acetylcysteine administration on pulmonary $\mathrm{O}(2)$ uptake kinetics and exercise tolerance in humans. Respir Physiol Neurobiol 175(1): 121-129.

63. Reid MB, Stokic DS, Koch SM, Khawli FA, Leis AA (1994) N-acetylcysteine inhibits muscle fatigue in humans. J Clin Invest 94(6): 2468-2474.

64. Lands LC, Grey VL, Smountas AA (1999) Effect of supplementation with a cysteine donor on muscular performance. J Appl Physiol (1985) 87(4): 1381-1385.

65. Zembron Lacny A, Gajewski M, Szyszka K (2010) Zastosowanie związków siarkowych w sporcie; Glutation. Polish J Sport Med 26(5): 231-243.

66. Karelis AD, Messier V, Suppere C, Briand P, Rabasa Lhoret R (2015) Effect of cysteine-rich whey protein (immunocal $囚$ ) supplementation in combination with resistance training on muscle strength and lean body mass in non-frail elderly subjects: a randomized, double-blind controlled study. J Nutr Health Aging 19(5): 531-536.

67. Micke P, Beeh KM, Buhl R (2002) Effects of long-term supplementation with whey proteins on plasma glutathione levels of HIV-infected patients. Eur J Nutr 41(1): 12-18.

68. Ross EK, Winter AN, Wilkins HM, Sumner WA, Duval N, et al. (2014) A Cystine-Rich Whey Supplement (Immunocal ${ }^{\circledR}$ ) Delays Disease Onset and Prevents Spinal Cord Glutathione Depletion in the hSOD1(G93A) Mouse Model of Amyotrophic Lateral Sclerosis. Antioxidants (Basel) 3(4): 843-865.

69. Gleeson M (2008) Dosing and efficacy of glutamine supplementation in human exercise and sport training. J Nutr 138(10): 2045-2049.

70. Roth E (2008) Nonnutritive effects of glutamine. J Nutr 138(10): 20252031.

71. Phillips GC (2007) Glutamine: the nonessential amino acid for performance enhancement. Curr Sports Med Rep 6(4): 265-268.

72. Yu JC, Jiang ZM, Li DM (1999) Glutamine: a precursor of glutathione and its effect on liver. World J Gastroenterol 5(2): 143-146.

73. Amores Sanchez MI, Medina MA (1999) Glutamine, as a precursor of glutathione, and oxidative stress. Mol Genet Metab 67(2): 100-105.

74. Cruzat VF, Krause M, Newsholme P (2014) Amino acid supplementation and impact on immune function in the context of exercise. J Int Soc Sports Nutr 11(1): 61.

75. Koo GH, Woo J, Kang S, Shin KO (2014) Effects of Supplementation with BCAA and L-glutamine on Blood Fatigue Factors and Cytokines in Juvenile Athletes Submitted to Maximal Intensity Rowing Performance. J Phys Ther Sci 26(8): 1241-1246.

76. Sasaki E, Umeda T, Takahashi I, Arata K, Yamamoto Y, et al. (2013) Effect of glutamine supplementation on neutrophil function in male judoists. Luminescence 28(4): 442-449.
77. Parry Billings M, Budgett R, Koutedakis Y, Blomstrand E, Brooks S, et al. (1992) Plasma amino acid concentrations in the overtraining syndrome: possible effects on the immune system. Med Sci Sports Exerc 24(12): 1353-1358.

78. Dabidi Roshan V BH (2009) The Effect of the Short-Term Glutamine Supplementation on Exhaustive Exercise-Induced Changes in Immune System of Active Boys. World Journal of Sport Sciences 2(4): 222-230.

79. Hakimi M, Ghader Z (2012) The effects of glutamine supplementation on performance and hormonal responses in nonathlete male students during eight week resistance training. Journal of Human Sport and Exercise 7(4): 770-782.

80. Castell LM, Newsholme EA (1997) The effects of oral glutamine supplementation on athletes after prolonged, exhaustive exercise. Nutrition 13(7-8): 738-742.

81. Favano A, Santos Silva PR, Nakano EY, Pedrinelli A, Hernandez AJ, et al. (2008) Peptide glutamine supplementation for tolerance of intermittent exercise in soccer players. Clinics (Sao Paulo) 63(1):27-32.

82. Waddell D FK (2005) Effects of a Glutamine Supplement on the Skeletal Muscle Contractile Force of Mice. Am J Undergrad Res 4(2): 11-18.

83. Shay KP, Moreau RF, Smith EJ, Smith AR, Hagen TM (2009) Alpha-lipoic acid as a dietary supplement: Molecular mechanisms and therapeutic potential. Biochim Biophys Acta 1790(10): 1149-1160.

84. Khanna S, Atalay M, Laaksonen DE, Gul M, Roy S, et al. (1999) Sen CK. alpha-lipoic acid supplementation: tissue glutathione homeostasis at rest and after exercise. J Appl Physiol 86(4): 1191-1196.

85. Moini H, Packer L, Saris NE (2002) Antioxidant and prooxidant activities of alpha-lipoic acid and dihydrolipoic acid. Toxicol Appl Pharmacol 182(1): 84-90.

86. Burke DG, Chilibeck PD, Parise G, Tarnopolsky MA, Candow DG (2003) Effect of alpha-lipoic acid combined with creatine monohydrate on human skeletal muscle creatine and phosphagen concentration. Int J Sport Nutr Exerc Metab 13(3): 294-302.

87. Zembron Lacny A, Slowinska Lisowska M, Szygula Z, Witkowski K, Szyszka K (2009) The comparison of antioxidant and hematological properties of $\mathrm{N}$-acetylcysteine and alpha-lipoic acid in physically active males. Physiol Res 58(6): 855-861.

88. Lappalainen Z (2011) Effect of alpha-lipoic acid and time-of-day on interleukin-6 response to exhaustive exercise in humans. Afr J Pharm Pharmacol 5(1): 42-47.

89. Pedersen BK, Steensberg A, Fischer C, Keller C, Ostrowski K, et al. (2001) Exercise and cytokines with particular focus on muscle-derived IL-6. Exerc Immunol Rev 7: 18-31.

90. Pedersen BK, Febbraio MA (2007) Interleukin-6 does/does not have a beneficial role in insulin sensitivity and glucose homeostasis - Point: Interleukin- 6 does have a beneficial role in insulin sensitivity and glucose homeostasis. J Appl Physiol 102(2): 814-816.

91. Pedersen BK, Steensberg A, Keller P, Keller C, Fischer C, et al. (2003) Muscle-derived interleukin-6: lipolytic, anti-inflammatory and immune regulatory effects. Pflugers Arch 446(1): 9-16.

92. Morawin B, Turowski D, Naczk M, Siatkowski I, Zembron Lacny A (2014) The combination of alpha-lipoic acid intake with eccentric exercise modulates erythropoetin relase. Biol Sport 31(3): 179-185.

93. Wang L, Jia Y, Rogers H, Suzuki N, Gassmann M, et al. (2013) Erythropoietin contributes to slow oxidative muscle fiber specification via PGC-1alpha and AMPK activation. Int J Biochem Cell Biol 45(7):11551164.

94. Polyviou TP, Pitsiladis YP, Lee WC, Pantazis T, Hambly C, et al. (2012) Thermoregulatory and cardiovascular responses to creatine, glycerol and alpha lipoic acid in trained cyclists. J Int Soc Sports Nutr 9(1): 29.

95. Henriksen EJ (2006) Exercise training and the antioxidant alpha-lipoic 
acid in the treatment of insulin resistance and type 2 diabetes. Free Radic Biol Med 40(1): 3-12.

96. Saengsirisuwan V, Kinnick TR, Schmit MB, Henriksen EJ (2001) Interactions of exercise training and lipoic acid on skeletal muscle glucose transport in obese Zucker rats. J Appl Physiol (1985) 91(1): 145-153.

97. Hamano Y (2006) Effects of dietary lipoic acid on plasma lipid, in vivo insulin sensitivity, metabolic response to corticosterone and in vitro lipolysis in broiler chickens. Br J Nutr 95(6): 1094-1101.

98. Saengsirisuwan V, Perez FR, Sloniger JA, Maier T, Henriksen EJ (2004) Interactions of exercise training and alpha-lipoic acid on insulin signaling in skeletal muscle of obese Zucker rats. Am J Physiol Endocrinol Metab 287(3): 529-536.

99. Barkoukis V, Lazuras L, Lucidi F, Tsorbatzoudis H (2015) Nutritional supplement and doping use in sport: Possible underlying social cognitive processes. Scand J Med Sci Sports 25(6): 582-588.

100. Maddock RJ, Casazza GA, Buonocore MH, Tanase C (2011) Vigorous exercise increases brain lactate and Glx (glutamate plus glutamine): A dynamic 1H-MRS study. Neuroimage 57(4): 1324-1330.

101. Morente Sanchez J, Zabala M (2013) Doping in sport: a review of elite athletes' attitudes, beliefs, and knowledge. Sports Med 43(6): 395-411.

102. Kwiatkowska D, Wojtowicz M, Jarek A, Goebel C, Chajewska K, et al. (2015) N,N-dimethyl-2-phenylpropan-1-amine - new designer agent

ISSN: 2574-1241

DOI: $10.26717 / B J S T R .2019 .12 .002293$

Dorota Kwiatkowska. Biomed J Sci \& Tech Res

(c) (i) This work is licensed under Creative Commons Attribution 4.0 License

Submission Link: https://biomedres.us/submit-manuscript.php found in athlete urine and nutritional supplement. Drug Test Anal 7(4): 331-335.

103. Cholbinski P, Wicka M, Kowalczyk K, Jarek A, Kaliszewski P, et al. (2014) Detection of beta-methylphenethylamine, a novel doping substance, by means of UPLC/MS/MS. Anal Bioanal Chem 406(15): 3681-3688.

104. (2018) World Anti-Doping Agency. The 2018 Prohibited List.

105. Koehler K, Parr MK, Geyer H, Mester J, Schanzer W (2009) Serum testosterone and urinary excretion of steroid hormone metabolites after administration of a high-dose zinc supplement. Eur J Clin Nutr 63(1): 65-70.

106. Petroczi A, Taylor G, Naughton DP (2011) Mission impossible? Regulatory and enforcement issues to ensure safety of dietary supplements. Food Chem Toxicol 49(2): 393-402.

107. Pokrywka A, Obminski Z, Malczewska Lenczowska J, Fijalek Z, Turek Lepa E, et al. (2014) Insights into Supplements with Tribulus Terrestris used by Athletes. J Hum Kinet 41: 99-105.

108. Van Thuyne W,Van Eenoo P, Delbeke FT (2006) Nutrtional supplements: prevalence of use and contamination with doping agents. Nutr Res Rev 19(1):147-158.

109. Gomes E (2013) The Indiscriminate Use of Supplements. J Sports Med Doping Stud 3(3).

BIOMEDICAL
RESEARCHES $\quad \begin{aligned} & \text { Assets of Publishing with us } \\ & \text { - Global archiving of articles }\end{aligned}$

Cite this article: Krzysztof Grucza, Piotr Chołbiński, Dorota Kwiatkowska, Mirosław Szutowski. Effects of Supplementation with Glutathione and its Precursors on Athlete Performance. Biomed J Sci \& Tech Res 12(4)-2019. BJSTR. MS.ID.002293. DOI: 10.26717/ BJSTR.2019.12.002293. 